\title{
Impact of Preparative pH on the Morphology and Photocatalytic Activity of $\mathrm{BiVO}_{4}$
}

\author{
Yongbiao Wan, ${ }^{1,2}$ Sihong Wang, ${ }^{3}$ Wenhao Luo, ${ }^{1}$ and Lianhua Zhao ${ }^{1}$ \\ ${ }^{1}$ Department of Chemistry, College of Science, Yanbian University, Jilin, Yanji 133002, China \\ ${ }^{2}$ Xinxiang Institute of Occupational Disease Prevention and Control, Henan, Xinxiang 453000, China \\ ${ }^{3}$ Analysis and Test Center, Yanbian University, Jilin, Yanji 133002, China
}

Correspondence should be addressed to Lianhua Zhao, zhaolh1031@yahoo.com.cn

Received 5 April 2012; Accepted 9 May 2012

Academic Editor: Jiaguo Yu

Copyright () 2012 Yongbiao Wan et al. This is an open access article distributed under the Creative Commons Attribution License, which permits unrestricted use, distribution, and reproduction in any medium, provided the original work is properly cited.

\begin{abstract}
Adjusting $\mathrm{pH}$ with an ammonia solution during the synthesis, single-crystalline $\mathrm{BiVO}_{4}$ has been prepared using $\mathrm{Bi}\left(\mathrm{NO}_{3}\right)_{3} \cdot 5 \mathrm{H}_{2} \mathrm{O}$ and $\mathrm{NH}_{4} \mathrm{VO}_{3}$ as starting materials through aqueous-phase precipitation at room temperature. The prepared samples are characterized by X-ray diffraction (XRD), diffuse reflectance spectroscopy (DRS), X-ray photoelectron spectroscopy (XPS), and scanning electron microscope (SEM). The impact of $\mathrm{pH}$ on structure, surface morphology, visible-light photocatalytic activity, and light absorption performance of $\mathrm{BiVO}_{4}$ is explored and discussed. During the synthesis process, neither extremely acidic (low $\mathrm{pH}$ ) nor basic (high $\mathrm{pH}$ ) conditions are desirable for the formation of $\mathrm{BiVO}_{4}$ in monoclinic phase. The highest photocatalytic performance on the degradation of a methylene blue solution is observed under $\mathrm{pH}=7.0$ for $\mathrm{BiVO}_{4}$ in monoclinic scheelite, which is attributed to its small grain size and marked surface oxygen evolution ability.
\end{abstract}

\section{Introduction}

Titanium dioxide and other semiconductor photocatalysts have been intensively studied for wide potential applications in water and air purification and solar energy conversion since Fujishima and Honda first reported the photocatalytic splitting of water on $\mathrm{TiO}_{2}$ electrodes in 1972 [19]. Among the various oxide and nonoxide semiconductor photocatalysts, titanium dioxide has proven to be the most suitable for widespread environmental applications due to its chemical and biological inertness, very strong oxidizing properties, low cost-effectiveness, and long-term stability against photocorrosion and chemical corrosion $[7,8]$. However, a large intrinsic band gap of $\mathrm{TiO}_{2}(3.2 \mathrm{eV}$ for anatase and $3.0 \mathrm{eV}$ for rutile) allows only a small portion of the solar spectrum in the ultraviolet light region to be absorbed. Therefore, effective utilization of visible light has become one of the most difficult challenges in photocatalysis, and it is highly desirable to develop a photocatalyst that can use visible light in high efficiency under sunlight irradiation [6-9].
Bismuth vanadate $\left(\mathrm{BiVO}_{4}\right)$ has attracted more and more attention as visible-light-response photocatalyst [10-16]. According to previous reports, $\mathrm{BiVO}_{4}$ appears in three main crystalline phases: monoclinic scheelite $(\mathrm{s}-\mathrm{m})$, tetragonal zircon $(\mathrm{z}-\mathrm{t})$, and tetragonal scheelite ( $\mathrm{s}-\mathrm{t})$ [17-19]. Among these forms, $\mathrm{BiVO}_{4}(\mathrm{~s}-\mathrm{m})$ presents strong visible-light catalytic properties [14-16], because the energy gap of $\mathrm{BiVO}_{4}(\mathrm{~s}-\mathrm{m})$ is merely $2.41 \mathrm{eV}$, and the absorptive wavelength is $515 \mathrm{~nm}$ [14]. Therefore, a wide range of exciting light results in high catalytic activity. It is well known that the catalytic activity is influenced by many factors such as structure, crystallite dimension, and surface appearance [20-23]. Moreover, the activity is strongly connected to the preparation method and conditions of the catalyst.

$\mathrm{BiVO}_{4}(\mathrm{~s}-\mathrm{m})$ is usually prepared through solid-state reaction at high temperature [24, 25]. Hydrothermal synthesis [13, 26-28], organometallic decomposition [29], and aqueous-phase precipitation $[11,12,30,31]$ have also been reported to obtain $\mathrm{BiVO}_{4}(\mathrm{~s}-\mathrm{m})$. As discussed by Kudo and coworkers [11], it took a long time to prepare $\mathrm{BiVO}_{4}$ with different structures through aqueous-phase precipitation 
using particular starting materials (e.g., $\mathrm{K}_{2} \mathrm{~V}_{5} \mathrm{O}$ and $\mathrm{KV}_{3} \mathrm{O}_{8}$ ) at room temperature. Utilizing $\mathrm{Bi}\left(\mathrm{NO}_{3}\right)_{3}$ and $\mathrm{NH}_{4} \mathrm{VO}_{3}$ as starting materials, $\mathrm{Yu}$ and coworkers obtained $\mathrm{BiVO}_{4}$ (sm) through calcination at $250^{\circ} \mathrm{C}[12]$, and they studied the correlation between the calcination temperature and crystalline phase in an ammonia solution. Furthermore, using the same starting materials, Ke and coworkers prepared $\mathrm{BiVO}_{4}(\mathrm{~s}-\mathrm{m})$ through aqueous-phase precipitation mixed with carbamide at $364^{\circ} \mathrm{C}$ [30]. Utilizing $\mathrm{NaVO}_{3}$ as the vanadium source, Gao and coworkers successfully prepared $\mathrm{BiVO}_{4}(\mathrm{~s}-\mathrm{m})$ through aqueous-phase precipitation at $150^{\circ} \mathrm{C}$ [31].

$\mathrm{BiVO}_{4}$ powders have also been synthesized through different templating routes. For example, Li and coworkers synthesized $\mathrm{BiVO}_{4}$ (s-m) using mesoporous silica KIT-6 as a hard template [32]. Ke and coworkers selectively prepared $\mathrm{BiVO}_{4}$ through a hydrothermal process using cetyltrimethylammonium bromide as a template-directing agent [27]. However, the template-assisted route not only increases the cost but also makes it more difficult to scale up due to its complexity and the limited capability of a template. To our best knowledge, little has been reported on the synthesis of $\mathrm{BiVO}_{4}(\mathrm{~s}-\mathrm{m})$ with various morphologies through regulating $\mathrm{pH}$ in convenient aqueous-phase precipitation, along with its visible-light photocatalytic activity. In this paper, utilizing aqueous-phase precipitation with $\mathrm{Bi}\left(\mathrm{NO}_{3}\right)_{3} \cdot 5 \mathrm{H}_{2} \mathrm{O}$ and $\mathrm{NH}_{4} \mathrm{VO}_{3}$ as starting materials, single-crystalline $\mathrm{BiVO}_{4}$ (s$\mathrm{m}$ ) is successfully prepared. The impact of $\mathrm{pH}$ on structure, surface topography, visible-light photocatalytic activity, and light absorption performance of $\mathrm{BiVO}_{4}(\mathrm{~s}-\mathrm{m})$ is investigated, and the results are discussed.

\section{Experimental}

2.1. Preparation of $\mathrm{BiVO}_{4}$. Equimolar amounts of $\mathrm{NH}_{4} \mathrm{VO}_{3}$ and $\mathrm{Bi}\left(\mathrm{NO}_{3}\right)_{3} \cdot 5 \mathrm{H}_{2} \mathrm{O}$ were dissolved consecutively into a nitric acid solution, and the mixture was kept stirring for $30 \mathrm{~min}$. To the mixture was slowly added an $\mathrm{NH}_{4} \mathrm{VO}_{3}$ solution to give a uniform and transparent saffron yellow solution. An orange precipitate was obtained after the $\mathrm{pH}$ was adjusted by dropwise adding an ammonia solution under stirring. The precipitate was then filtered, rinsed with distilled water, and dried at 25,80 , or $110^{\circ} \mathrm{C}$ to give a final product.

2.2. Characterization. X-ray diffraction (XRD) patterns were measured on an X-ray diffractometer (Rigaku dmax/IIIC) with $\mathrm{Cu} \mathrm{Ka}$ radiation (tube voltage $=35 \mathrm{KV}$, tube current $=15 \mathrm{~mA}$ ) in order to analyze the structure of $\mathrm{BiVO}_{4}$. DRS patterns were obtained to appraise the light absorption performance of samples. Scanning electron microscope (SEM, HITACHI S-3500N) was used to observe the micromorphology. Absorbance for degradation of a methylene blue (MB) solution was measured on a UV-vis spectrophotometer (U-3010, Hitachi). X-ray photoelectron spectroscopy (XPS) patterns were measured using X-ray photoelectron spectroscopy (ESCALAB MK II) to analyze the surface components with $\mathrm{Al} \mathrm{K \alpha}$ radiation, and all spectra

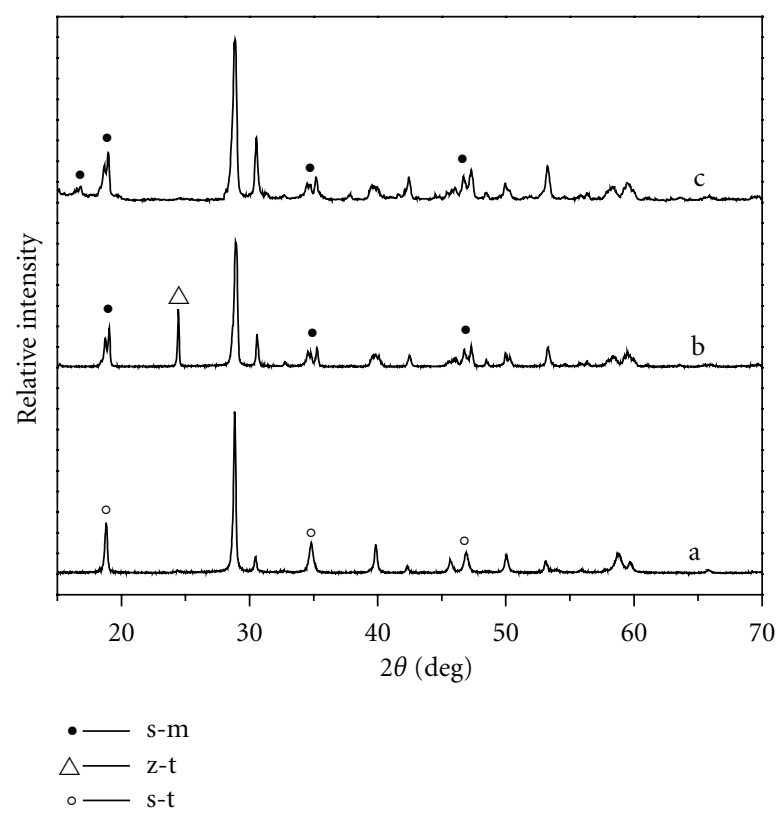

FIGURE 1: XRD patterns of samples at different temperature. (a): $25^{\circ} \mathrm{C},(\mathrm{b}): 80^{\circ} \mathrm{C},(\mathrm{c}): 110^{\circ} \mathrm{C}$.

were referenced by setting the hydrocarbon C1s peak to $285.0 \mathrm{eV}$ to compensate for residual charging effects.

2.3. Measurements of Photocatalytic Activity. Photocatalytic decomposition of a methylene blue (MB) solution was used to evaluate the photocatalytic properties of the synthesized materials. A photocatalyst powder $(0.10 \mathrm{~g})$ was dispersed in an $\mathrm{MB}$ solution $(100 \mathrm{~mL})$ in a reaction cell with a magnetic stirrer. A $300 \mathrm{~W}$ Xe-illuminator (light intensity = $3.5 \mathrm{~mW} / \mathrm{cm}^{2}$ ) was used as a light source, and a cutoff filter $(\lambda>420 \mathrm{~nm})$ was employed for visible-light irradiation in order to decolorate. At irradiation time intervals of $1 \mathrm{~h}$, suspensions $(4.0 \mathrm{~mL})$ were collected and subsequently centrifuged to remove photocatalyst particles. A spectrophotometer was used to analyze the absorbance. Destruction rates were calculated with formula: $D=\left(C_{0}-C\right) / C_{0} \times$ $100 \%$ ( $D$ : destruction rate; $C_{0}$ : initial concentration; $C$ : concentration in different batches).

\section{Results and Discussion}

3.1. Formation of $\mathrm{BiVO}_{4}$ with Different Crystal Phase. Although similar to the XRD pattern of $\mathrm{BiVO}_{4}(\mathrm{~s}-\mathrm{t})$ due to the same scheelite structures, the XRD pattern of $\mathrm{BiVO}_{4}$ (s$\mathrm{m})$ exhibits a weak diffraction peak at $15^{\circ}$. There are apparent splitting peaks at $2 \theta=18.5,35$, and $46^{\circ}$, which are attributed to the $\mathrm{Bi}-\mathrm{O}$ polyhedron in $\mathrm{BiVO}_{4}(\mathrm{~s}-\mathrm{m})$ containing a $6 \mathrm{~s}^{2}$ lone pair in $\mathrm{Bi}^{3+}$ [12].

Figure 1 shows XRD patterns of samples calcined at different temperatures. All the diffraction peaks of $\mathrm{BiVO}_{4}$ fit well with the standard Joint Committee on Powder Diffraction Standards (JCPDS) card for $\mathrm{BiVO}_{4}(\mathrm{~s}-\mathrm{t}$ ) (JCPDS 
no. 75-2481, space group: I41/amd, unit cell parameters: $a=$

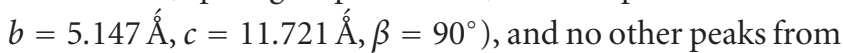
impurities are detected. The results suggest that $\mathrm{BiVO}_{4}(\mathrm{~s}-\mathrm{t})$ can be successfully synthesized at room temperature $\left(25^{\circ} \mathrm{C}\right)$, which is consistent with Kudo's et al. studies [11]. When the reaction temperature increases to $80^{\circ} \mathrm{C}$, the diffraction peaks of the resulting powders can be indexed to $\mathrm{BiVO}_{4}$ (z-t) (JCPDS no. 14-0133, space group: I41/amd, unit cell

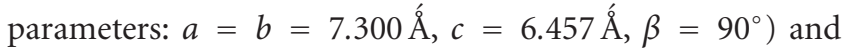
$\mathrm{BiVO}_{4}$ (s-m) (JCPDS no. 14-0688, space group: I2/amd, unit

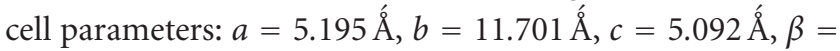
$\left.90.38^{\circ}\right)$. These findings indicate that the resulting powders are the mixtures of $\mathrm{BiVO}_{4}(\mathrm{~s}-\mathrm{m})$ and $\mathrm{BiVO}_{4}(\mathrm{~s}-\mathrm{t})$. As the treatment temperature increases to $110^{\circ} \mathrm{C}, \mathrm{BiVO}_{4}(\mathrm{~s}-\mathrm{m})$ is obtained.

In general, $\mathrm{BiVO}_{4}(\mathrm{~s}-\mathrm{m})$ and $\mathrm{BiVO}_{4}(\mathrm{~s}-\mathrm{t})$ are obtained at high temperatures. In this work, two different singlecrystalline $\mathrm{BiVO}_{4}(\mathrm{~s}-\mathrm{m})$ and $\mathrm{BiVO}_{4}(\mathrm{~s}-\mathrm{t})$ are successfully prepared at low temperature. Moreover, the photocatalytic activity of $\mathrm{BiVO}_{4}(\mathrm{~s}-\mathrm{m})$ is superior to that of $\mathrm{BiVO}_{4}(\mathrm{~s}-\mathrm{t})$. To optimize the process conditions for $\mathrm{BiVO}_{4}(\mathrm{~s}-\mathrm{m})$, the impact of different $\mathrm{pH}$ on the formation of crystalline $\mathrm{BiVO}_{4}$ at $110^{\circ} \mathrm{C}$ is studied as shown in Figure 2.

3.2. Impact of Preparative $\mathrm{pH}$ on the Formation of $\mathrm{BiVO}_{4}$. Figure 2 shows the XRD patterns of the samples prepared under different $\mathrm{pH}$ at $110^{\circ} \mathrm{C}$. The peaks of the powders under $\mathrm{pH}=1.0$ and 10.0 can both be indexed to mixtures of $\mathrm{BiVO}_{4}$ (z-t) and $\mathrm{BiVO}_{4}$ (s-m) (JCPDS no. 14-0133 and no. 140688 ), while the samples under $\mathrm{pH}=3.0,5.0$, and 7.0 are $\mathrm{BiVO}_{4}(\mathrm{~s}-\mathrm{m})$ only. Therefore, $\mathrm{BiVO}_{4}(\mathrm{~s}-\mathrm{m})$ can be selectively synthesized simply by adjusting $\mathrm{pH}$. During the synthetic process, neither extreme acidic (low $\mathrm{pH}$ ) nor basic (high $\mathrm{pH})$ conditions are desirable to the formation of monoclinic phase.

The average particle size of the samples is calculated using the Scherrer equation [6],

$$
D=\frac{K\left(\lambda \times\left(180^{\circ} / \pi\right)\right)}{\left(\sqrt{\beta^{2}-S^{2}}\right) \cos \theta_{\beta}},
$$

where $D$ is the apparent crystallite mean size, perpendicular to the reflecting plane, $K$ the shape factor ( 0.9 for spherical crystallite), $\lambda$ the radiation wavelength $\left(1.5406 \mathrm{~A}^{\circ}\right), S$ the instrumental line broadening $\left(0.001^{\circ}\right), \beta$ the reflection width at half-maximum intensity (FWHM), and $\theta_{\beta}$ is the angle at the maximum intensity. The results are summarized in Table 1. Under extreme acidic (low $\mathrm{pH}, \mathrm{pH}=1.0$ ) or basic (high $\mathrm{pH}, \mathrm{pH}=10.0$ ) conditions, only $\mathrm{BiVO}_{4}(\mathrm{z}-\mathrm{t})$ is formed with a large particle size. The sample grain obtained in the presence of ammonia decreases gradually with an increasing amount of ammonia, and in the end it transforms into $\mathrm{BiVO}_{4}$ (s-m).

According to Tokunaga's et al. view [14], although $\mathrm{BiVO}_{4}$ $(\mathrm{s}-\mathrm{m})$ is thermodynamically more stable than $\mathrm{BiVO}_{4}(\mathrm{z}-\mathrm{t})$ at room temperature, the formation of $\mathrm{BiVO}_{4}(\mathrm{z}-\mathrm{t})$ seems to be favored kinetically with a sudden increase in $\mathrm{pH}$ by adding a base. $\mathrm{BiVO}_{4}(\mathrm{z}-\mathrm{t})$ with a large particle size shows no phase

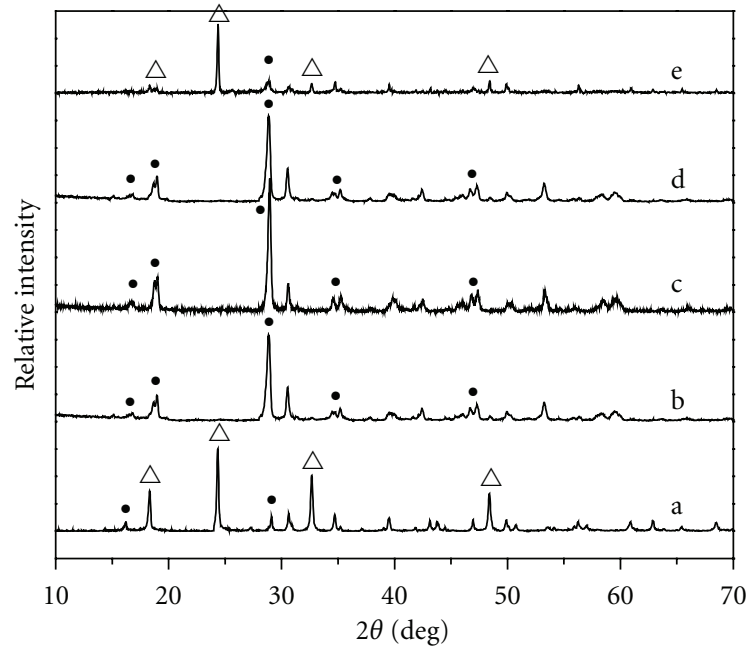

Figure 2: XRD patterns of samples under different $\mathrm{pH} .(\triangle-$ tetragonal zircon type, $\bullet-$ monoclinic scheelite type). (a) $\mathrm{pH}=1.0$, (b) $\mathrm{pH}=3.0$, (c) $\mathrm{pH}=5.0$, (d) $\mathrm{pH}=7.0$, (e) $\mathrm{pH}=10.0$.

TABLE 1: Crystal size of samples different $\mathrm{pH}$ at $110^{\circ} \mathrm{C}$.

$\begin{aligned} & \text { Samples under } \\ & \text { different } \mathrm{pH}\end{aligned} \mathrm{pH}=1.0 \mathrm{pH}=3.0 \mathrm{pH}=5.0 \mathrm{pH}=7.0 \mathrm{pH}=10.0$

$\begin{array}{llllll}\text { Crystal size/nm } & 38.1 & 23.9 & 22.3 & 19.4 & 49.6\end{array}$

transform into the thermodynamically stable $\mathrm{BiVO}_{4}(\mathrm{~s}-\mathrm{m})$ at room temperature. The particle size becomes smaller during the preparation after dissolution and recrystallization, and $\mathrm{BiVO}_{4}(\mathrm{~s}-\mathrm{m})$ is finally formed after recrystallization and/or in the small particles, where the stress can be released.

3.3. Impact of Preparative $\mathrm{pH}$ on the Morphology of $\mathrm{BiVO}_{4}$. Figure 3 shows SEM micrographs of $\mathrm{BiVO}_{4}$ under different preparative $\mathrm{pH}$ at $110^{\circ} \mathrm{C}$, with significant differences found in the morphology and particle shape. When the $\mathrm{pH}$ of the solution is approximately neutral, the particle size of the samples is $19.4 \mathrm{~nm}$, while when the condition is extremely acidic or basic, the particle size becomes relatively larger. The results are consistent with Table 1. Obviously, the $\mathrm{pH}$ of the synthesis solution has a significant impact on the morphologies and particle size of the final products.

\subsection{Impact of Preparative $\mathrm{pH}$ on the Optical Absorption Per-} formance of $\mathrm{BiVO}_{4}$. Figure 4 presents the DRS spectra of $\mathrm{BiVO}_{4}$ prepared under different $\mathrm{pH}$ at $110^{\circ} \mathrm{C}$. Although there are some differences in the absorption band of $\mathrm{BiVO}_{4}$ under different preparative $\mathrm{pH}$, all absorption bands are found in the visible range. Samples prepared under extremely acidic ( $\mathrm{pH}=1.0)$ or basic $(\mathrm{pH}=10.0)$ conditions exhibit blue-shift in the spectra when compared with those under $\mathrm{pH}=3.0$, 5.0, and 7.0, and the optical absorption performance of the former is weaker than that of the latter. The absorption band in the visible-light region is attributed to the band transition from a $\mathrm{Bi}_{6 s}$ and $\mathrm{O}_{2 \mathrm{p}}$ valence band to a $\mathrm{V}_{3 \mathrm{~d}}$ conduction band [29]. If an absorption band is different, both the relevant 


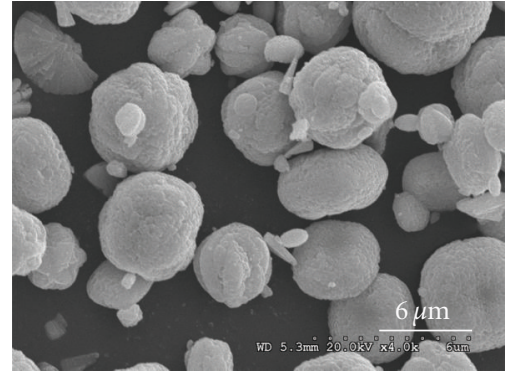

(a)

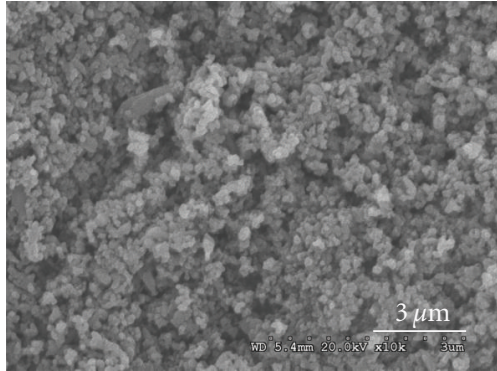

(b)

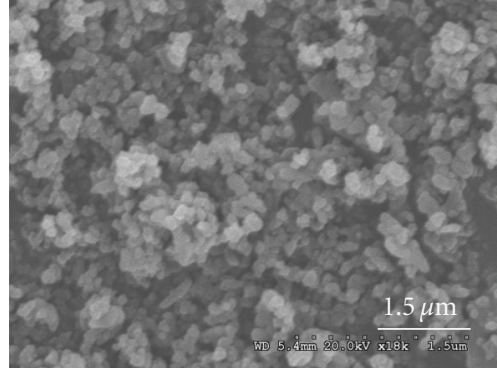

(c)

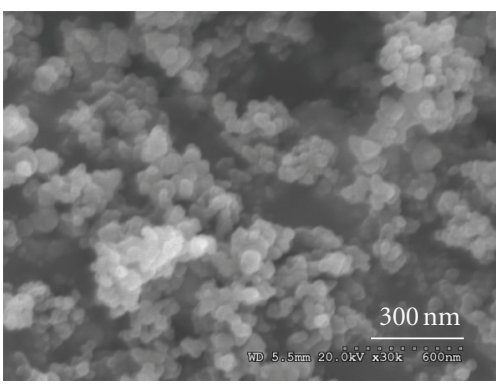

(d)

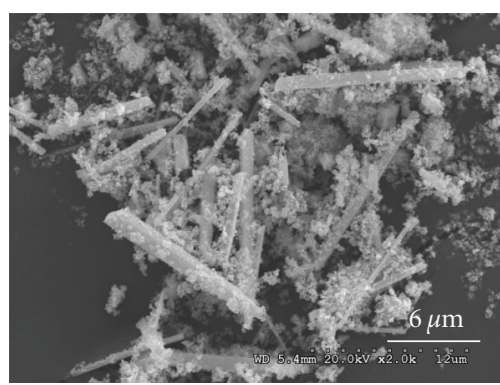

(e)

Figure 3: SEM images of $\mathrm{BiVO}_{4}$ under different $\mathrm{pH}$ at $110^{\circ} \mathrm{C}$. (a) $\mathrm{pH}=1.0$, (b) $\mathrm{pH}=3.0$, (c) $\mathrm{pH}=5.0$, (d) $\mathrm{pH}=7.0,(\mathrm{e}) \mathrm{pH}=10.0$.

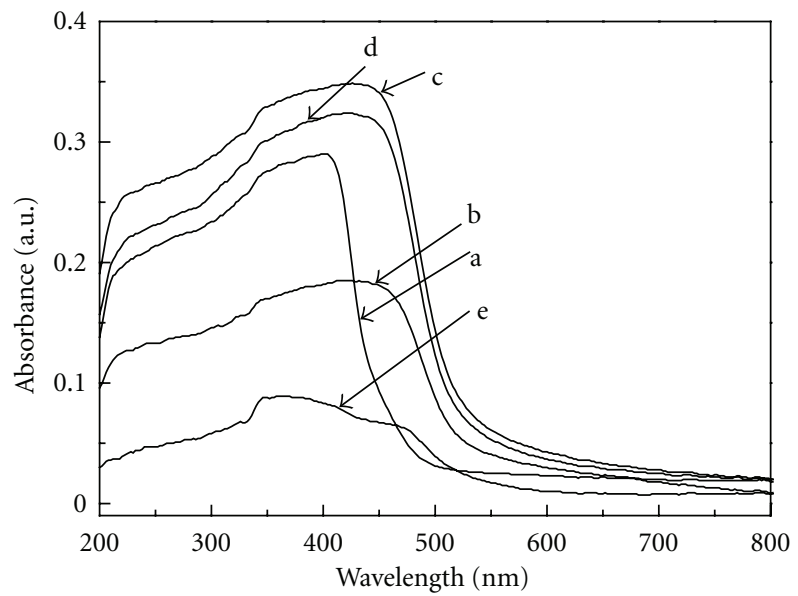

FIGURE 4: DRS spectra of samples under different $\mathrm{pH}$ at $110^{\circ} \mathrm{C}$. (a) $\mathrm{pH}=1.0$, (b) $\mathrm{pH}=3.0$, (c) $\mathrm{pH}=5.0$, (d) $\mathrm{pH}=7.0$, (e) $\mathrm{pH}=10.0$.

conduction and valence band energy level are also difference. The band gap $\left(E_{g}, \mathrm{eV}\right)$ is calculated using the equation $E_{g}=$ $1240 / \lambda$, where $\lambda$ is the wavelength of the absorption bands. The band gap of $\mathrm{BiVO}_{4}(\mathrm{z}-\mathrm{t})$ is slightly wider than that of $\mathrm{BiVO}_{4}(\mathrm{~s}-\mathrm{m})$. If the $\mathrm{BiVO}_{4}(\mathrm{~s}-\mathrm{m})$ content is low and its band gap is relatively wide, the absorption band will be blueshifted. According to the DRS spectra, low $\mathrm{BiVO}_{4}$ (s-m) contents are obtained under extremely acidic $(\mathrm{pH}=1.0)$ or basic $(\mathrm{pH}=10.0)$ conditions, while under $\mathrm{pH}=3.0,5.0$, and 7.0 , only $\mathrm{BiVO}_{4}(\mathrm{~s}-\mathrm{m})$ is formed. This is consistent with the $\mathrm{XRD}$ results. The low optical absorption performance of the samples under extremely acidic $(\mathrm{pH}=1.0)$ or basic $(\mathrm{pH}=$ $10.0)$ conditions may be attributed to their weak crystallinity.

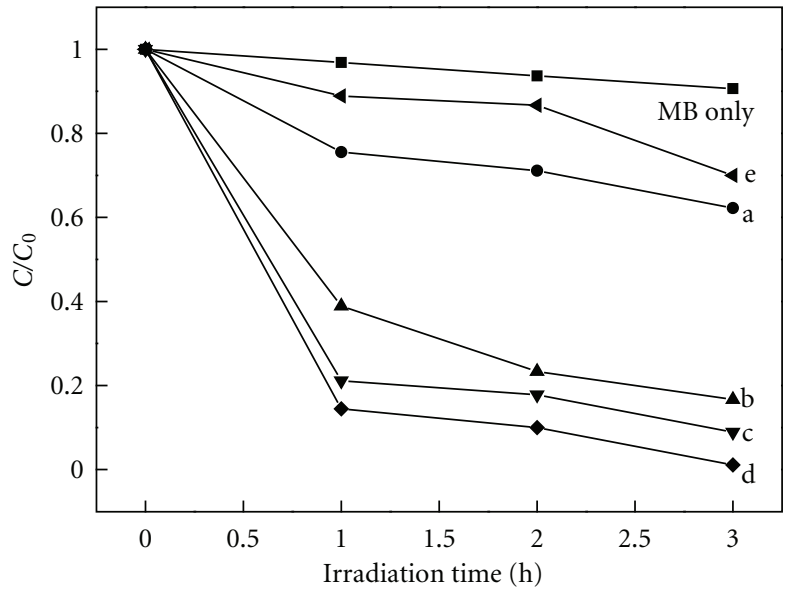

FIGURE 5: Photocatalytic activities of samples under different $\mathrm{pH}$ at $110^{\circ} \mathrm{C}$. (a) $\mathrm{pH}=1.0$, (b) $\mathrm{pH}=3.0$, (c) $\mathrm{pH}=5.0$, (d) $\mathrm{pH}=7.0$, (e) $\mathrm{pH}=10.0$.

3.5. Impact of Preparative $\mathrm{pH}$ on the Photocatalytic Activity of $\mathrm{BiVO}_{4}$. The photocatalytic activities of $\mathrm{BiVO}_{4}$ are measured on the degradation of an $\mathrm{MB}$ solution in a liquid medium under a visible-light irradiation. Figure 5 presents the $\mathrm{MB}$ concentration $\left(C / C_{0}\right)$ in a function of the irradiation time over samples under different preparative $\mathrm{pH}$ at $110^{\circ} \mathrm{C}$. As shown in Figure 5, the photocatalytic activity of $\mathrm{BiVO}_{4}$ (s$\mathrm{m})$ is generally higher than the mixtures of $\mathrm{BiVO}_{4}(\mathrm{z}-\mathrm{t})$ and $\mathrm{BiVO}_{4}(\mathrm{~s}-\mathrm{m})$. Especially, the decoloration rate of $\mathrm{MB}$ over the sample under $\mathrm{pH}=7.0$ is $98.9 \%$ after $3 \mathrm{~h}$ of irradiation, and the sample also exhibits the highest photocatalytic activity. The decoloration rates are $91.2 \%$ and $84.0 \%$ over 


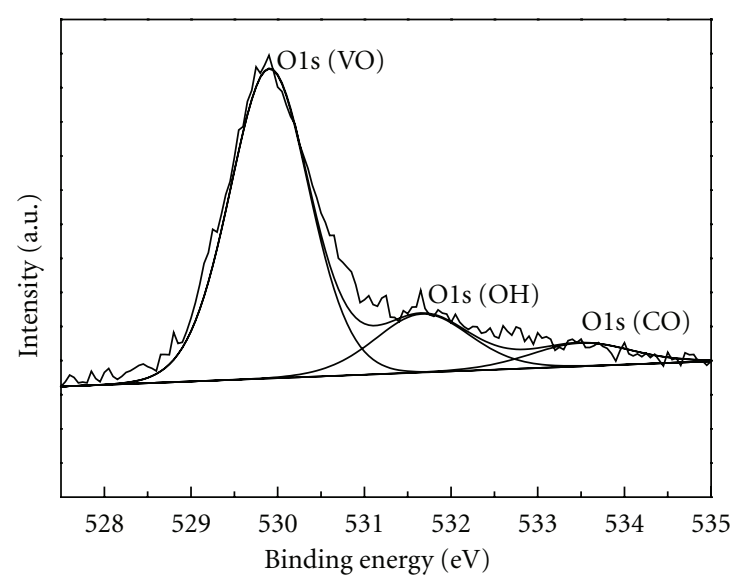

(a)

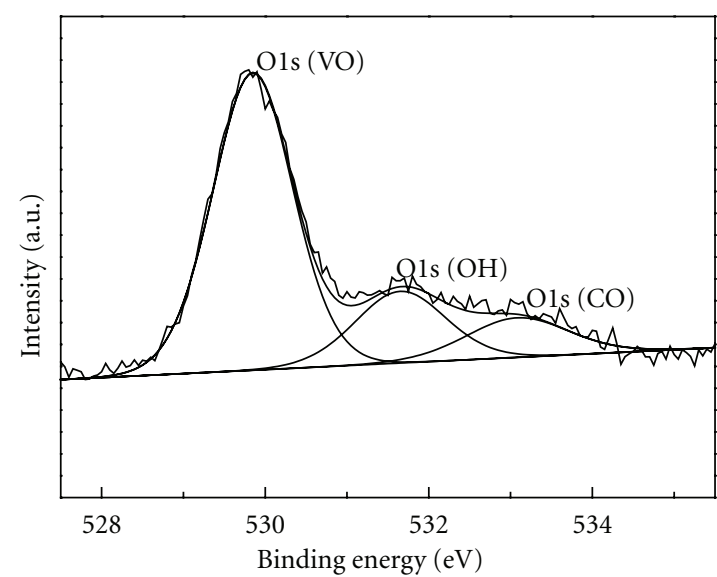

(b)

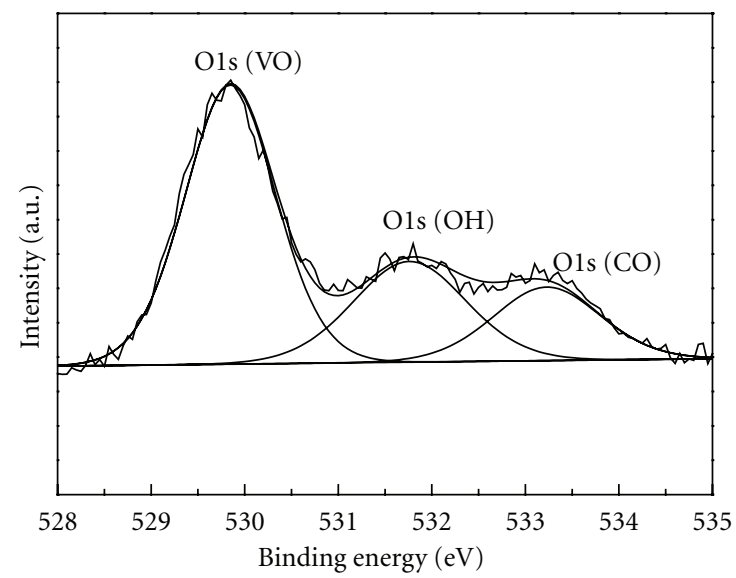

(c)

FIGURE 6: XPS spectra of $\mathrm{BiVO}_{4}$ (s-m) under different pH. (a) $\mathrm{pH}=3.0$, (b) $\mathrm{pH}=5.0$, (c) $\mathrm{pH}=7.0$.

the samples under $\mathrm{pH}=5.0$ and 3.0, respectively. However, the photocatalytic activities of the samples under $\mathrm{pH}=1.0$ and 10.0 are both low, whose decoloration rates are $38.0 \%$ and $30.0 \%$, respectively.

It is widely believed that the photocatalytic activity is directly affected by the particle size of a catalyst. The smaller the particle size is, the larger the specific surface area becomes. The different particle size in Table 1 also explains the order for the photocatalytic activity of the samples under different $\mathrm{pH}$. The average grain size of the sample under $\mathrm{pH}=$ 7.0 is the smallest, which possesses the highest photocatalytic activity.

3.6. X-Ray Photoelectron Spectroscopy Analysis. In order to explore the surface adsorption of $\mathrm{OH}^{-}$on the catalyst surface, XPS analysis was performed. The XPS spectra of $\mathrm{BiVO}_{4}(\mathrm{~s}-\mathrm{m})$ under different $\mathrm{pH}$ are shown in Figure 6. The three fitting peaks of $\mathrm{O} 1 \mathrm{~s}$ are from lattice oxygen (VO), adsorbed oxygen $(\mathrm{OH}$, binding energy: $532 \mathrm{eV})$, and carbon oxygen (CO, binding energy: $553 \mathrm{eV}$ ). A C-O bond is formed from carbon impurities in the air and adsorbed oxygen on the surface of catalyst. The percentages of the fitting peak area on the lattice oxygen (VO), adsorbed oxygen $(\mathrm{OH})$, and carbon oxygen (CO) are summarized in Table 2.

Table 2 summaries the results of the curve-fitting of the high resolution XPS spectra of $\mathrm{BiVO}_{4}(\mathrm{~s}-\mathrm{m})$ for the $\mathrm{O} 1 \mathrm{~s}$ region under different $\mathrm{pH}$. With an increasing $\mathrm{pH}$, the relative content of adsorbed oxygen increases gradually. Photocatalytic reactions are usually caused by photoelectrons and holes separated, which can provide highly active $\mathrm{OH}^{*}$ [33]. A strong oxide free radical, $\mathrm{OH}^{\circ}$, has no selectivity toward oxidizing certain organic compounds. Therefore, the better separation between photoelectron and hole attribute to the higher surface adsorbed oxygen contents. Sequentially, the quantum efficiency of the catalyst is enhanced. Usually, adsorbed oxygen and carbon oxygen reflect the surface adsorption ability of a photocatalyst. The surface-adsorbed oxygen content of the sample under $\mathrm{pH}=7.0$ is the highest $(25.57 \%+17.61 \%)$, so it exhibits a high photocatalytic activity.

\section{Conclusions}

Single-crystalline $\mathrm{BiVO}_{4}(\mathrm{~s}-\mathrm{m})$ has been synthesized through aqueous-phase precipitation at $\mathrm{pH}$ ranging from 3.0 to 
TABLE 2: Binding energy and area percentage of $\mathrm{BiVO}_{4}(\mathrm{~s}-\mathrm{m})$ for the $\mathrm{O} 1 \mathrm{~s}$ region under different $\mathrm{pH}$.

\begin{tabular}{lccc}
\hline \multirow{2}{*}{ Samples } & \multicolumn{3}{c}{ Bonding energy/eV (ri/\%) } \\
& O1s (VO) & O1s $(\mathrm{OH})$ & O1s (CO) \\
\hline $\mathrm{pH}=3.0$ & $529.90(75.76 \%)$ & $531.67(16.67 \%)$ & $533.50(7.58 \%)$ \\
$\mathrm{pH}=5.0$ & $529.85(69.44 \%)$ & $531.65(18.75 \%)$ & $533.08(11.82 \%)$ \\
$\mathrm{pH}=7.0$ & $529.85(56.82 \%)$ & $531.76(25.57 \%)$ & $533.23(17.61 \%)$ \\
\hline
\end{tabular}

ri/\%: area percentage of O1s fitting peaks.

7.0 regulated with an ammonia solution. The morphology, surface texture, and grain size of the synthesized $\mathrm{BiVO}_{4}$ are significantly dependent on the preparative $\mathrm{pH}$. Under $\mathrm{pH}=$ 1.0 and 10.0 conditions, mixtures of $\mathrm{BiVO}_{4}(\mathrm{~s}-\mathrm{t})$ and $\mathrm{BiVO}_{4}$ (s-m) are obtained, while under $\mathrm{pH}=3.0-7.0$, only $\mathrm{BiVO}_{4}$ $(\mathrm{s}-\mathrm{m})$ is prepared. Therefore, $\mathrm{BiVO}_{4}(\mathrm{~s}-\mathrm{m})$ can be selectively synthesized simply by adjusting the preparative $\mathrm{pH}$. The band gap of $\mathrm{BiVO}_{4}(\mathrm{~s}-\mathrm{m})$ is $2.4 \mathrm{eV}$ when it is prepared under $\mathrm{pH}=5.0$ and 7.0.

The overlap between the $\mathrm{Bi}_{6 s}$ and $\mathrm{O}_{2 \mathrm{p}}$ orbitals in the valence band results in an increase in hole mobility. Both the surface oxygen evolution ability and grain size have significant impacts on the photocatalytic performance for the degradation of a methylene blue solution under a visiblelight irradiation.

\section{Acknowledgment}

This work is supported by the National Natural Science Foundation of China (NSFC) (Grant no. 20563004).

\section{References}

[1] A. Fujishima and K. Honda, "Electrochemical photolysis of water at a semiconductor electrode," Nature, vol. 238, no. 5358, pp. 37-38, 1972.

[2] M. R. Hoffmann, S. T. Martin, W. Choi, and D. W. Bahnemann, "Environmental applications of semiconductor photocatalysis," Chemical Reviews, vol. 95, no. 1, pp. 69-96, 1995.

[3] Q. Xiang, J. Yu, and M. Jaroniec, "Graphene-based semiconductor photocatalysts," Chemical Society Reviews, vol. 41, no. 2, pp. 782-796, 2012.

[4] Q. Li, B. Guo, J. Yu et al., "Highly efficient visible-light-driven photocatalytic hydrogen production of CdS-cluster-decorated graphene nanosheets," Journal of the American Chemical Society, vol. 133, no. 28, pp. 10878-10884, 2011.

[5] J. Zhang, J. Yu, Y. Zhang, Q. Li, and J. R. Gong, "Visible light photocatalytic $\mathrm{H}_{2}$-production activity of $\mathrm{CuS} / \mathrm{ZnS}$ porous nanosheets based on photoinduced interfacial charge transfer," Nano Letters, vol. 11, no. 11, pp. 4774-4779, 2011.

[6] B. D. Cullity, Elements of X-Ray Diffraction, Addison-Wesley, San Francisco, Calif, USA, 1978.

[7] S. Liu, J. Yu, and M. Jaroniec, "Anatase $\mathrm{TiO}_{2}$ with dominant high-energy $\{001\}$ facets: synthesis, properties, and applications," Chemistry of Materials, vol. 23, no. 18, pp. 4085-4093, 2011.

[8] A. Kubacka, M. Fernández-García, and G. Colón, "Advanced nanoarchitectures for solar photocatalytic applications," Chemical Reviews, vol. 112, no. 3, pp. 1555-1614, 2012.
[9] M. Romero, J. Blanco, B. Sánchez et al., "Solar photocatalytic degradation of water and air pollutants: challenges and perspectives," Solar Energy, vol. 66, no. 2, pp. 169-182, 1999.

[10] X. Zhang, Z. Ai, F. Jia, L. Zhang, X. Fan, and Z. Zou, "Selective synthesis and visible-light photocatalytic activities of $\mathrm{BiVO}_{4}$ with different crystalline phases," Materials Chemistry and Physics, vol. 103, no. 1, pp. 162-167, 2007.

[11] A. Kudo, K. Omori, and H. Kato, "A novel aqueous process for preparation of crystal form-controlled and highly crystalline $\mathrm{BiVO}_{4}$ powder from layered vanadates at room temperature and its photocatalytic and photophysical properties," Journal of the American Chemical Society, vol. 121, no. 49, pp. 1145911467, 1999.

[12] J. Yu, Y. Zhang, and A. Kudo, "Synthesis and photocatalytic performances of $\mathrm{BiVO}_{4}$ by ammonia co-precipitation process," Journal of Solid State Chemistry, vol. 182, no. 2, pp. 223228, 2009.

[13] J. Yu and A. Kudo, "Effects of structural variation on the photocatalytic performance of hydrothermally synthesized $\mathrm{BiVO}_{4}, "$ Advanced Functional Materials, vol. 16, no. 16, pp. 2163-2169, 2006.

[14] S. Tokunaga, H. Kato, and A. Kudo, "Selective preparation of monoclinic and tetragonal $\mathrm{BiVO}_{4}$ with scheelite structure and their photocatalytic properties," Chemistry of Materials, vol. 13, no. 12, pp. 4624-4628, 2001.

[15] S. Kohtani, J. Hiro, N. Yamamoto, A. Kudo, K. Tokumura, and R. Nakagaki, "Adsorptive and photocatalytic properties of Agloaded $\mathrm{BiVO}_{4}$ on the degradation of 4-n-alkylphenols under visible light irradiation," Catalysis Communications, vol. 6, no. 3, pp. 185-189, 2005.

[16] S. Kohtani, M. Koshiko, A. Kudo et al., "Photodegradation of 4-alkylphenols using $\mathrm{BiVO}_{4}$ photocatalyst under irradiation with visible light from a solar simulator," Applied Catalysis B, vol. 46, no. 3, pp. 573-586, 2003.

[17] J. D. Bierlein and A. W. Sleight, "Ferroelasticity in $\mathrm{BiVO}_{4}$," Solid State Communications, vol. 16, no. 1, pp. 69-70, 1975.

[18] L. Hoffart, U. Heider, R. A. Huggins, W. Witschel, R. Jooss, and A. Lentz, "Crystal growth and conductivity investigations on $\mathrm{BiVO}_{4}$ single crystals," Ionics, vol. 2, no. 1, pp. 34-38, 1996.

[19] L. Zhou, W. Wang, L. Zhang, H. Xu, and W. Zhu, "Singlecrystalline $\mathrm{BiVO}_{4}$ microtubes with square cross-sections: microstructure, growth mechanism, and photocatalytic property," Journal of Physical Chemistry C, vol. 111, no. 37, pp. 13659-13664, 2007.

[20] P. Madhusudan, J. Ran, J. Zhang, J. Yu, and G. Liu, "Novel urea assisted hydrothermal synthesis of hierarchical $\mathrm{BiVO}_{4} /$ $\mathrm{Bi}_{2} \mathrm{O}_{2} \mathrm{CO}_{3}$ nanocomposites with enhanced visible-light photocatalytic activity," Applied Catalysis B, vol. 110, pp. 286-295, 2011.

[21] P. B. Avakyan, M. D. Nersesyan, and A. G. Merzhanov, "New materials for electronic engineering," American Ceramic Society Bulletin, vol. 75, no. 2, pp. 50-55, 1996.

[22] P. Shuk, H. D. Wiemhöfer, U. Guth, W. Göpel, and M. Greenblatt, "Oxide ion conducting solid electrolytes based on $\mathrm{Bi}_{2} \mathrm{O}_{3}$," Solid State Ionics, vol. 89, no. 3-4, pp. 179-196, 1996.

[23] K. Shantha and K. B. R. Varma, "Preparation and characterization of nanocrystalline powders of bismuth vanadate," Materials Science and Engineering B, vol. 60, no. 1, pp. 66-75, 1999.

[24] A. W. Sleight, H. Y. Chen, A. Ferretti, and D. E. Cox, "Crystal growth and structure of $\mathrm{BiVO}_{4}$, " Materials Research Bulletin, vol. 14, no. 12, pp. 1571-1581, 1979. 
[25] A. R. Lim, S. H. Choh, and M. S. Jang, "Prominent ferroelastic domain walls in $\mathrm{BiVO}_{4}$ crystal," Journal of Physics: Condensed Matter, vol. 7, no. 37, pp. 7309-7323, 1995.

[26] T. Yang, D. Xia, G. Chen, and Y. Chen, "Influence of the surfactant and temperature on the morphology and physicochemical properties of hydrothermally synthesized composite oxide $\mathrm{BiVO}_{4}, "$ Materials Chemistry and Physics, vol. 114, no. 1, pp. 69-72, 2009.

[27] D. Ke, T. Peng, L. Ma, P. Cai, and K. Dai, "Effects of hydrothermal temperature on the microstructures of $\mathrm{BiVO}_{4}$ and its photocatalytic $\mathrm{O}_{2}$ evolution activity under visible light," Inorganic Chemistry, vol. 48, no. 11, pp. 4685-4691, 2009.

[28] B. Cheng, W. Wang, L. Shi, J. Zhang, J. Ran, and H. Yu, "One-pot template-free hydrothermal synthesis of monoclinic $\mathrm{BiVO}_{4}$ hollow microspheres and their enhanced visible-light photocatalytic activity," International Journal of Photoenergy, vol. 2012, Article ID 797968, 10 pages, 2012.

[29] K. Sayama, A. Nomura, Z. Zou, R. Abe, Y. Abe, and H. Arakawa, "Photoelectrochemical decomposition of water on nanocrystalline $\mathrm{BiVO}_{4}$ film electrodes under visible light," Chemical Communications, vol. 9, no. 23, pp. 2908-2909, 2003.

[30] D. Ke, T. Peng, L. Ma, P. Cai, and P. Jiang, "Photocatalytic water splitting for $\mathrm{O}_{2}$ production under visible-light irradiation on $\mathrm{BiVO}_{4}$ nanoparticles in different sacrificial reagent solutions," Applied Catalysis A, vol. 350, no. 1, pp. 111-117, 2008.

[31] S. M. Gao, Q. A. Qiao, P. P. Zhao et al., "Synthesis of different morphologies and structures of nano-sized $\mathrm{BiVO}_{4}$ by precipitation method," Chinese Journal of Inorganic Chemistry, vol. 23, no. 7, pp. 1153-1159, 2007.

[32] G. Li, D. Zhang, and J. C. Yu, "Ordered mesoporous $\mathrm{BiVO}_{4}$ through nanocasting: a superior visible light-driven photocatalyst," Chemistry of Materials, vol. 20, no. 12, pp. 3983-3992, 2008.

[33] B. Ohtani, Y. Okugawa, S. I. Nishimoto, and T. Kagiya, "Photocatalytic activity of $\mathrm{TiO}_{2}$ powders suspended in aqueous silver nitrate solution. Correlation with $\mathrm{pH}$-dependent surface structures," Journal of Physical Chemistry, vol. 91, no. 13, pp. 3550-3555, 1987. 


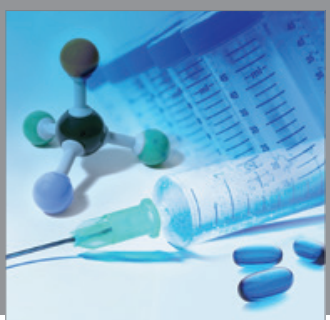

International Journal of

Medicinal Chemistry

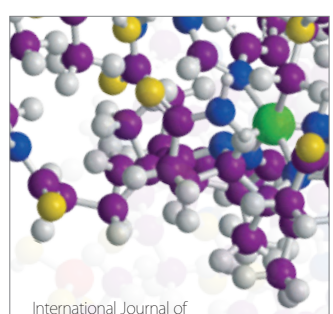

Carbohydrate Chemistry

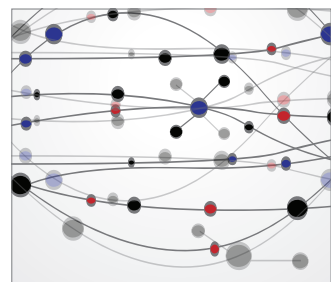

The Scientific World Journal
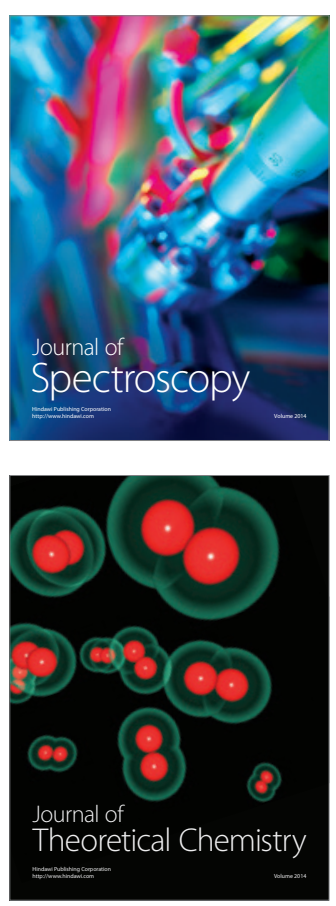
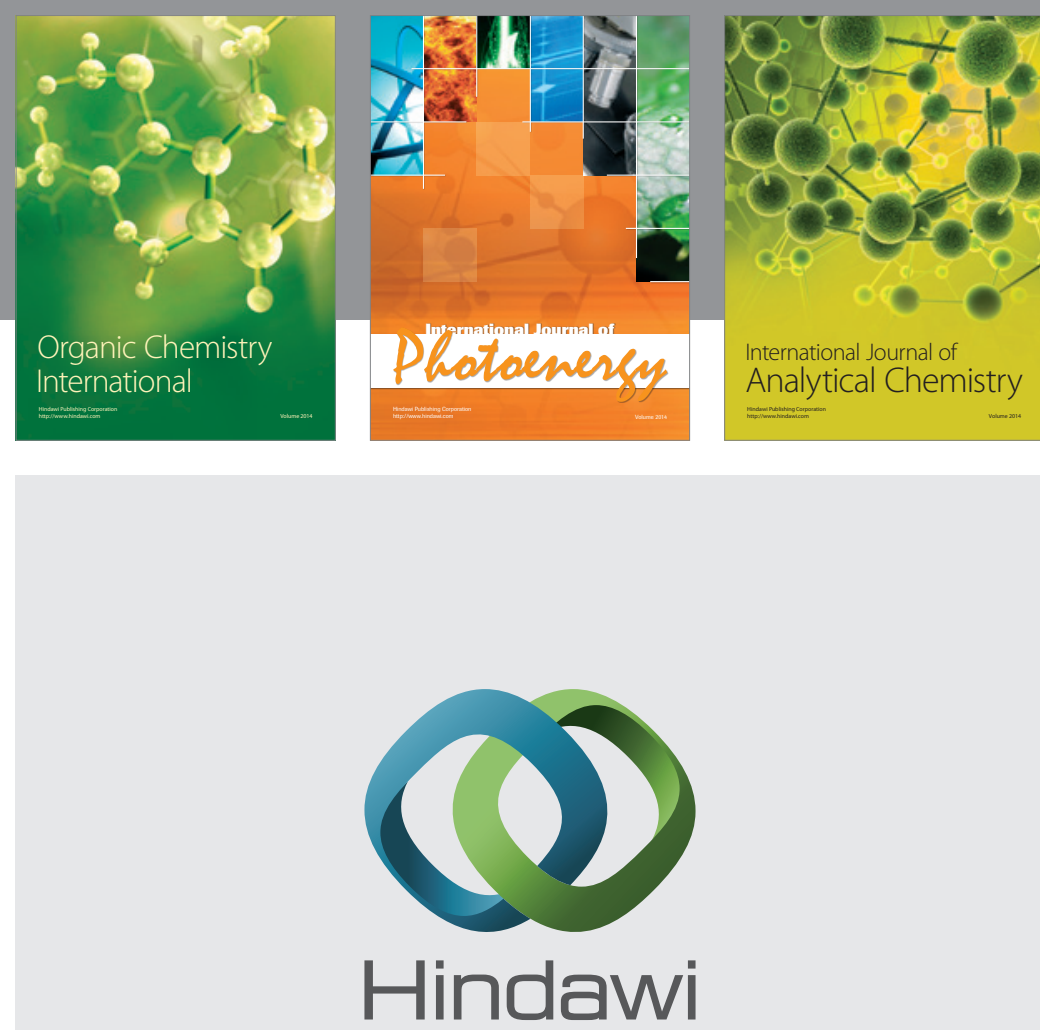

Submit your manuscripts at

http://www.hindawi.com
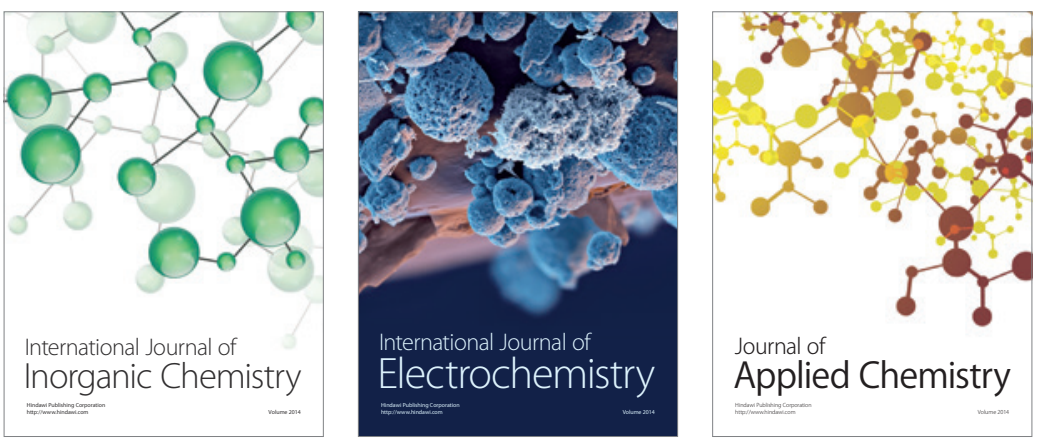

Journal of

Applied Chemistry
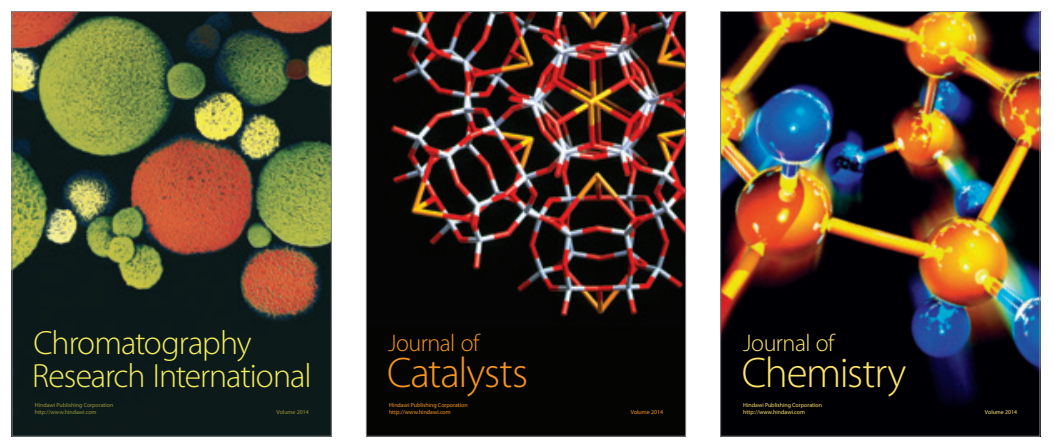
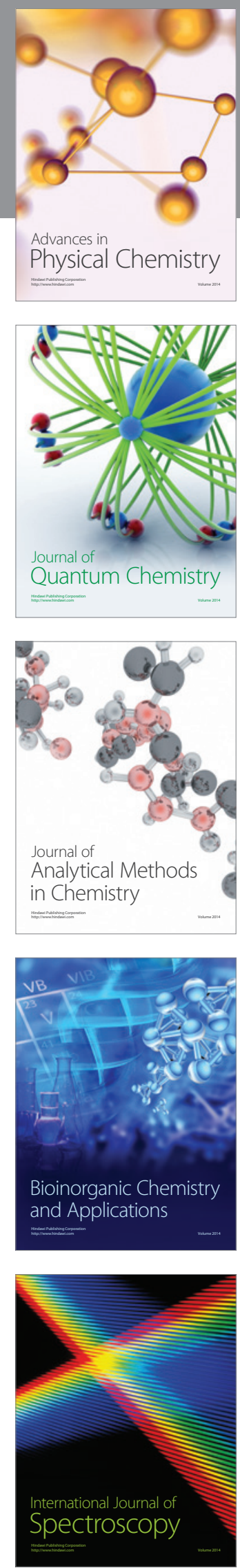